\title{
O Discurso dos \#ProtestosBR: análise de conteúdo do Twitter ${ }^{1}$
}

\author{
Raquel Recuero \\ Gabriela Zago \\ Marco Toledo Bastos
}

Resumo: $\mathrm{O}$ artigo foca na análise do discurso de mensagens no Twitter relacionadas aos protestos que ocorreram, em junho, no Brasil. Nosso objetivo é discutir as relações entre os conceitos e suas redes de sentido de forma a desvelar características e elementos que conformem padrões discursivos. Como principais resultados, discutimos o uso do Twitter para narrar os protestos e mobilizar as pessoas, mais do que efetivamente para discuti-los, bem como a presença de atores-chave, contextos e demandas, além do foco na narrativa ao vivo, o uso de hashtags panfletárias e a localização específica dos tweets.

Palavras-chave: protestos; discurso; análise de conteúdo; twitter.

Abstract: The Discourse of \#ProtestosBR: content analysis of Twitter - This paper focus on an analysis of the discourse of Twitter messages during the protests in Brazil during June 2013. Our objective is to discuss how the concepts relate to each other and form networks of meanings around the tweets about the protests. Our search for common characteristics and elements reveals how Twitter was used to describe the protests and to mobilize people rather than to discuss what was actually taking place. We describe the key actors, contexts and demands, as well as the focus on live narratives, \#pamphleteer hashtags, and the specific location of tweets.

Keywords: protests; discourse; content analysis; twitter.

\section{Introdução}

Em junho de 2013, o Brasil foi palco de alguns dos maiores protestos de sua história recente. Durante vários dias, em diversas cidades e regiões do País, mais de dois milhões de pessoas foram às ruas pedindo mudanças. O que diferenciou essas manifestações, entretanto, foi o uso dos sites de rede social como Twitter ${ }^{2}$ e Facebook ${ }^{3}$ durante

1 Projeto desenvolvido com o apoio do CNPq, processo número 408650/2013-3.

2 Disponível em: <http://twitter.com>.

3 Disponível em: <http://facebook.com>. 
o desenrolar dos eventos. Essas ferramentas tiveram um papel expressivo na organização e na reverberação dos protestos, como aliás tem ocorrido em outras regiões do mundo (BURNS; ELTHAM, 2009 e BASTOS, RAIMUNDO e TRAVITZKI, 2012).

Neste artigo, nosso objetivo é compreender esses eventos através de uma análise de conteúdo. Assim, as questões de pesquisa, que guiam o trabalho, são: (1) Quais são as características dos discursos sobre os protestos?; (2) Quais as diferenças de discursos entre as diferentes regiões brasileiras?; (3) Quais discursos a rede de coocorrências desvela? Para discutir essas questões, empregamos uma análise de conteúdo de foco referencial (Bardin, 2004) de 218.568 tweets publicados entre os dias 14 e 20 de junho de 2013.

\section{O advento dos "Protestos em Rede"}

O uso de sites de rede social como espaço para o ativismo político já foi documentado por diversos autores. Castells (2012), por exemplo, entende que tais protestos, que coexistem nos ambientes on-line e off-line, são "movimentos sociais em rede" e argumenta que dependem das mídias sociais para sua estruturação, constituindo um "espaço público híbrido de liberdade", onde manifestantes de ambos os "lados" (on-line e off-line) participam na revolução.

\section{Twitter, Localização e Protestos}

O papel do Twitter na organização e participação de protestos e movimentos foi estudado por diversos autores. Gleason (2013, online) estudou o movimento Occupy e discutiu o papel do Twitter como criador de oportunidades de participação: "desde criar, taguear e compartilhar conteúdo até ler, assistir e seguir uma hashtag ${ }^{4 \prime 5}$. De forma parecida, Penney e Dadas (2013) identificaram sete papéis sobrepostos de participação no Twitter durante o movimento Occupy: (1) facilitação de protestos face a face, (2) cobertura ao vivo de protestos face a face, (3) retuite de informações e incorporação de links, (4) expressão de visões pessoais sobre o movimento, (5) envolvimento em discussões sobre o movimento, (6) estabelecimento de conexões com outros ativistas e (7) facilitação de ações on-line. Esses papéis indicam formas por meio das quais a ferramenta foi utilizada nessas manifestações.

Malini e Antoun (2013), comentando o movimento \#12M (também dentro do Occupy), discutem o papel dos retweets e das hashtags na organização e repercussão das ações políticas. Nessa linha, Bastos, Raimundo e Travitzki (2012) também investigaram as hashtags políticas, classificando seu papel como "panfletagem", no sentido de que parte de sua motivação é espalhar a ideia e obter apoio, o que poderia ser discutido como mais

4 A hashtag é uma "etiqueta", um termo ou conjunto de termos que é marcado com o sinal "\#”. Ela é buscável e todos os tweets que possuem a marcação podem ser recuperados em uma única busca.

5 Tradução de: "from creating, tagging, and sharing content to reading, watching, and following a hashtag". 
um dos objetivos dos papéis de participação na ferramenta. Cancian, Moura e Malini (2013) também discutem o papel das hashtags, mas focando seu papel de unificação das narrativas.

Gutierrez (2013) destaca, como características desses movimentos organizados em rede (e especialmente via Twitter), o desaparecimento dos mediadores tradicionais (atores como sindicatos, partidos e grupos), a não presença de lideranças, a convocação "em torno de causas concretas e de fácil adesão" (Ibid., p. 2). Toret (2012), falando sobre o \#15M, caracteriza esses elementos como parte da característica híbrida desses movimentos, onde as multidões transformam, através de sua "capacidade tecnopolítica" 6 o "mal-estar individual" em processos de politização coletiva.

A função democrática da mídia social ${ }^{7}$ em políticos foi desafiada por outros estudos. Burns e Eltham (2009) estudaram as limitações da mídia social para os protestos do Irã, revelando que o mesmo Twitter, que serviu aos ativistas, serviu também ao governo para “identificar e caçar os manifestantes pró-democracia" ${ }^{\text {. }}$ Ou seja, a mesma ferramenta que permite aos manifestantes se organizarem e atuarem também permite a reação e repressão governamental. Nesse sentido, Howard e Hussain (2011) explicam que, embora potencialmente democráticas, as ferramentas digitais permitem aos governos autoritários reprimir ou impedir os protestos. Por outro lado, os autores ressaltam que essa mídia também permitiu que eventos localizados se tornassem movimentos estruturados diante de oportunidades de ação e amplificação.

Essa característica da amplificação é fundamental para que possamos compreender como protestos locais se tornam movimentos nacionais ou globais. Vallina-Rodriguez et al. (2011) fizeram uma ampla análise do movimento "Indignados" na Espanha, especialmente de hashtags e tweets e sua geolocalização. Os autores observaram que a participação de movimentos populares dominou os tweets, apagando a participação dos atores políticos tradicionais. A análise também mostrou o rápido espalhamento do movimento pela Espanha através da localização dos tweets e das intersecções entre tweets de localidades diferentes.

\section{Discursos e Twitter}

O termo "discurso", neste trabalho, é definido como uma forma de representação e reprodução ideológica, que compreende "o domínio geral de todas as afirmações, algumas vezes como um grupo individualizado de afirmações, outras vezes, como uma prática regulada que reflete um número de afirmações" (FOUCAULT, 1999, p. 80). O discurso, assim, não se resume ao enunciado, mas a um conjunto ideológico em que determinadas "formações discursivas" (Ibid.) estão presentes e para os quais os enunciados se filiam.

6 Capacidade de apropriação das tecnologias (CANCIAN; MOURA; MALINI, 2013).

7 Compreendemos aqui o termo "mídia social" como sinônimo da ação plural das redes sociais sobre os sites de rede social, gerando e negociando novos fluxos de informação.

8 Tradução de: "to identify and hunt down pro-democracy protestors." 
Assim, discurso, poder e ideologia são indissociáveis. Em sentido semelhante, Bourdieu (1991) foca as trocas linguísticas como "relações de poder simbólico", ou seja, momentos onde as relações de poder (e dominação) entre os falantes são atualizadas (ibid., p. 37). O discurso, assim, é uma imposição dos dominantes sobre os dominados que reconstrói e determina as estruturas da dominação e legitima a ordem social vigente. Bourdieu (1977) explicita que essas trocas linguísticas também dependem do que ele chama de "campo linguístico", a expressão das relações de força estabelecidas pela linguagem (ibid., p. 4).

Um dos motivos pelos quais muitos autores consideram o espaço on-line como democrático em termos de mídia é justamente o fato de permitir a publicação de discursos não hegemônicos e a pluralidade de formações discursivas. Assim, o estudo desses discursos pode desvelar estratégias e modos de ação de grupos filiados a outras formações no sentido de tentar construir maior visibilidade.

Dentre esses discursos, está o dos protestos e do ativismo. Malini e Antoun (2013, p. 249), por exemplo, referem-se a essas narrativas como contrárias à "naturalização do funcionamento do poder", como uma apropriação da estrutura pelos usuários como forma de democratizar as vozes e o acesso democrático. Lindgren e Lundstrom (2011) abordam a questão do ativismo on-line sob o ponto de vista discursivo e discutem o uso da hashtag \#WikiLeaks e seus padrões discursivos de forma semelhante ao proposto neste artigo. Os autores também utilizam a análise textual relacional para discutir as redes de coocorrência e desvelar o que chamam de discurso dos "piratas" no Twitter.

\section{Abordagem metodológica}

Dissemos, no início deste trabalho, que nossas questões de pesquisa focavam: (1) Quais são as características dos discursos sobre os protestos?; (2) Quais as diferenças de discursos entre as diferentes regiões brasileiras?; (3) Quais discursos a rede de coocorrências desvela? Nesse sentido, passaremos a discutir o método que utilizaremos para atingir esses objetivos.

\section{A análise de conteúdo referencial como método}

A análise de conteúdo (AC) é um tipo de análise textual que vem ganhando grande aceitação como método de estudo dos discursos on-line (Lindgren e Lundstrom, 2011). A AC tem várias formas e abordagens e permite o estudo dos rastros publicados no espaço digital tanto de forma qualitativa quanto de forma quantitativa (Bardin, 2004). O método da AC é bastante simples. Ele compreende fundamentalmente três procedimentos: codificação dos dados, categorização e inferência. A codificação implica na construção de categorias a partir de enumeração e agregação, criando-se elementos que representem 
o conteúdo observado (ibid., p. 97). A categorização compreende a construção de critérios e a classificação dos dados em conjuntos a partir deles. A inferência é a interpretação dos dados e das categorias a partir dos contextos da análise.

Neste trabalho, focaremos a análise de conteúdo de foco referencial, ou seja, um conjunto de técnicas de estudo das relações entre os conteúdos e conceitos, focando, principalmente, nas coocorrências e na estrutura da rede (Bardin, 2004). Este foco é bastante adequado para a extração de relações de grandes conjuntos de dados (Lindgren e Lundstrom, 2011), justamente porque permite a codificação de termos por frequência e correlações.

\section{Análise Estrutural de Redes Sociais}

A análise de redes sociais (ARS) é uma abordagem teórico-metodológica focada na análise da estrutura social e baseada no estudo dos atores sociais (nós ou nodos) e suas interconexões. Na ARS, há dois tipos de variáveis: as estruturais e as de composição (WASSERMAN; FAUST, 1994). As variáveis estruturais que utilizaremos neste trabalho, assim, referem-se à frequência de conexão (frequência em que aparecem juntas) das palavras utilizadas nos tweets e suas conexões. As variáveis de composição, por outro lado, referemse às palavras (conceitos), que aparecerem mais e com mais força nos tweets analisados.

Embora a ARS disponha de várias medidas e abordagens para analisar as estruturas do corpus, neste trabalho, focaremos algumas das mais simples:

a) Grau de conexão - o grau de conexão refere-se à "força" da conexão entre dois nós. O grau de conexão é uma medida numérica, normalmente referida como o somatório de todas as conexões existentes entre A e B.

b) Centralização - a centralização é uma medida focada no quão centralizado um grafo está em torno de determinados nós, focando em torno de quais pontos a rede está organizada.

c) Modularidade - a modularidade é uma medida de rede, de clusterização, de vizinhança dos nós. Ela divide a rede em grupos, de acordo com a força das conexões entre os diversos nós. Nós incluídos em um "módulo" têm conexões mais fortes entre si do que com os demais.

Embora este trabalho analise a materialidade dos discursos, esses discursos representam uma plêiade de atores e de práticas sociais que justificam a abordagem dos conceitos da ARS. Para analisar esses dados, utilizou-se o software Gephi ${ }^{9}$.

\section{Procedimentos metodológicos}

Para responder às questões de pesquisa elencadas neste trabalho, primeiramente procedeu-se à agregação de uma amostragem de conjunto de dados; depois à sua codificação, categorização e análise de coocorrências.

9 Software de visualização de redes. Disponível em: <https://gephi.org/>. 
a) Procedimentos de amostragem - como dissemos, iniciamos a coleta dos dados que são aqui apresentados no dia 14 de junho de 2013. A partir dessa data, foram coletados tweets através da API pública do Twitter de forma automática, utilizando-se scripts de coleta em R. Os tweets foram coletados a partir de um conjunto de palavras-chaves, tais como "protesto" e"manifestação", dentre outros. Esse conjunto de dados continha mais de três milhões de tweets. Os dados utilizados, neste trabalho, compreendem tweets publicados entre os dias 14 e 20 de junho de 2013, que foram filtrados pelo uso de hashtags localizadas (por exemplo, \#protestosp ou \#protestorj), o que constituiu um conjunto de 218.568 tweets. Depois da filtragem, os tweets foram categorizados por localização geográfica com base no conjunto de dados relativos à descrição, localização do tweet e localização do usuário. Em termos absolutos, tivemos a seguinte distribuição de tweets por região (Figura 1) ${ }^{10}$.

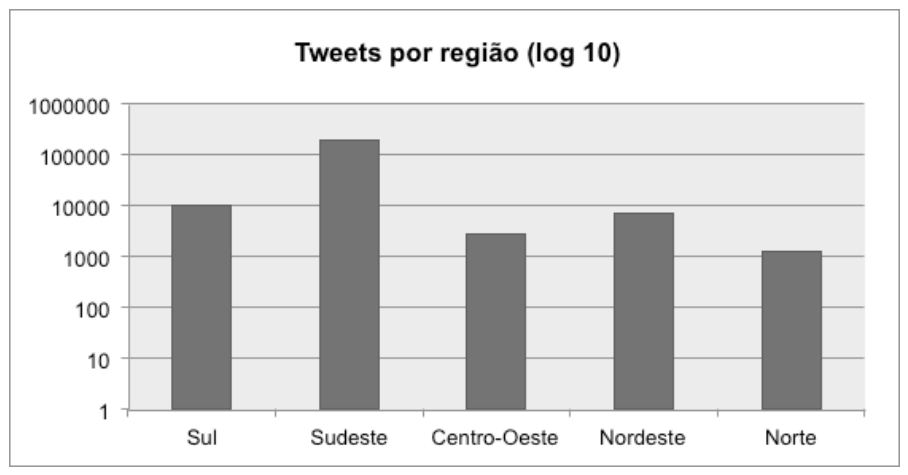

Fig.1. Tweets por região

Todos os estados brasileiros aparecem no dataset, embora de maneira desigual. Há muitos tweets localizados na região Sudeste em detrimento das demais regiões (197168 tweets). Nordeste (7367 tweets) e Sul (10062 tweets) aparecem bastante próximos (saliente-se que há, entretanto, mais estados no primeiro) e Centro-Oeste (2726 tweets) e Norte (1243 tweets).

b) Procedimentos de análise - os tweets foram separados por região do País. Dentro desses cinco conjuntos de dados, foram codificados os termos mais utilizados por frequência até o limite de 100 (cem termos) ${ }^{11}$, utilizando-se um conjunto de palavras a ser descartadas ("stopwords"). O foco foi semântico e foram privilegiados substantivos e adjetivos em detrimento de outros léxicos. Esses termos foram então codificados em categorias semânticas, de acordo com a proposta da AC. Assim, por exemplo, "manifestações", "manifestação" e "protesto" ficaram dentro da mesma categoria

10 Como a distribuição é bastante desigual, optamos por apresentar o gráfico em escala logarítmica para possibilitar que se vejam essas diferenças de forma mais clara.

11 Utilizamos o Textometrica. Disponível em: <http://textometrica.humlab.umu.se/>. 
"protestos". A seguir, aplicamos um processo de codificação conceitual às categorias, buscando incluir termos que se referissem ao mesmo evento. Assim, por exemplo, "protestos" inclui também "manifestantes".

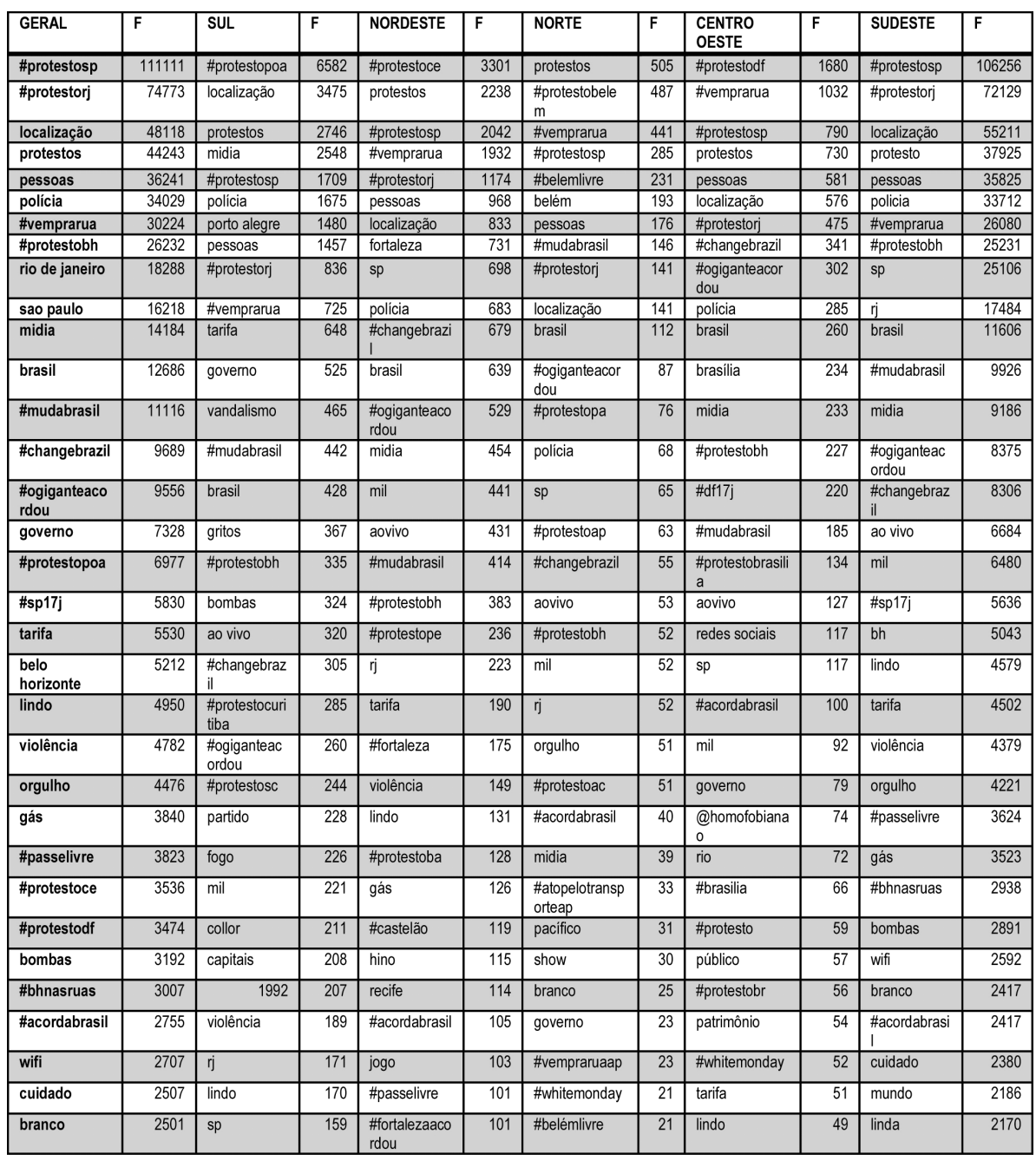

Tab. 1. Resumo dos Dados Classificados por Região ${ }^{12}$

Assim, as palavras foram codificadas dentro de um mesmo conceito quando seu sentido era o mesmo. Optamos por manter as hashtags em grupos separados no corpus,

12 Na tabela, há regiões com maior e menor número de conceitos. Aquelas onde há menor número de tweets para análise a tendência encontrada foi a de uma maior pluralidade de conceitos, por isso a diferença. O Termo " $F$ " refere-se à frequência do conceito nos dados. 
uma vez que a utilização desses termos não ocorre em todos os grupos, ao contrário dos demais termos analisados neste estudo. Esses conceitos foram, posteriormente, analisados por região e de forma geral (Tabela 1). Em seguida, foram ainda analisados em termos de coocorrências, ou seja, quais ocorreram mais em conjunto em um mesmo tweet. Com base na Tabela 1, foram montadas as redes de coocorrências mais fortes (normalizadas) dentro das cem palavras e conceitos mais frequentes.

\section{O discurso sobre os protestos no Twitter}

A seguir, detalharemos a análise dos dados coletados. Na primeira parte, enfocamos a análise de frequência dos conceitos encontrados nos dados. Na segunda, a análise de coocorrências e as redes em torno desses conceitos.

\section{Análise de frequência dos conceitos}

A Tabela 1 indica alguns padrões com base na frequência de conceitos geral e específica por região. Esses padrões são discutidos a seguir com base nos elementos do discurso e nas características da narrativa.

Elementos do Discurso: iniciaremos a análise trabalhando os conceitos que traduzem os elementos presentes nos dados dos discursos.

a) Principais atores - outro elemento que podemos observar nos termos e conceitos mais frequentes são os atores dos protestos. Primeiramente, aparecem em todos os dados os manifestantes, dentro da categoria "protestos". Também aparecem como atores as "pessoas", o "governo" e a "mídia". Na primeira categoria estão todos os termos referentes aos manifestantes e aos eventos dos protestos em si. Na categoria "pessoas" estão os termos referentes a pessoas em geral (não necessariamente participantes dos eventos). Na categoria "governo" estão as referências aos governantes de modo específico (por exemplo, "Dilma"). Finalmente, na categoria "mídia" foram reunidos os veículos midiáticos e suas referências. Vemos que a categoria "mídia" aparece em todos os grupos, mostrando a importância dos veículos na cobertura e na amplificação dos eventos. É importante salientar, entretanto, que a "mídia" citada varia bastante entre as localidades. A última categoria, que também compreende um dos principais atores dos protestos, é "polícia". Observa-se aqui a ausência de referências a coletivos, sindicatos e grupos tradicionais, apontando para a pluralidade da participação e sua não apropriação como movimento - de forma semelhante ao que Gutierrez (2013); Toret (2012) e Cancian, Moura e Malini (2013) apontam com relação aos atores e mobilizadores dos protestos.

De todas as categorias, "governo" foi a mais desigual. Referências específicas aos governantes aparecem apenas nos dados dos protestos da região Centro-Oeste 
(onde os protestos realizados em Brasília pesam bastante), da região Norte e da região Sul. Nos dados dos protestos do Sudeste e Nordeste essas referências existem em menor escala e não aparecem entre os termos mais citados. Tal ausência é significativa no sentido que mostra o "governo" como pouco presente no discurso. Ou seja, pouco se falou sobre e para o governo no período.

b) Reivindicações - a principal reivindicação que aparece no conjunto de dados analisados diz respeito, de modo específico, à tarifa de ônibus. Vemos, assim, que nos dados do período analisado, a questão da tarifa de ônibus tem uma frequência bastante significativa. Exceto na região Norte, o conceito "tarifa" apareceu em todos os dados, e em alguns espaços inclusive com a presença da hashtag \#passelivre, que fazia referência ao movimento que originou os protestos. Essa, entretanto, é a única reivindicação que aparece nos principais termos com maior frequência. Esse foco talvez seja uma consequência da fácil adesão a uma causa concreta como motivação (GUTIERREZ, 2013).

c) Contextos - finalmente, um último elemento relevante para o estudo dos protestos dentro desses elementos de análise são os contextuais, que aparecem nos protestos de forma mais abrangente. Assim, quais as diferenças e semelhanças podem ser observadas no discurso dos termos mais frequentes em cada região? A região Sul tem vários termos relacionados com a violência. Por exemplo, "bombas", "fogo", "gritos", "vandalismo", etc. constroem um conjunto discursivo bastante focado na questão da violência. Além disso, é a única região onde aparecem referências a 1992 e ao impeachment do então presidente Fernando Collor de Mello. Na região Nordeste, observamos uma grande quantidade de referências ao estádio "Castelão" e ao "jogo", referência ao jogo da seleção brasileira em Fortaleza durante o período, quando houve protestos tanto fora como dentro do estádio. Na região Norte, aparecem mais termos como "orgulho", "respeito", "linda" e etc. O foco dos discursos parece estar no elogio às manifestações e na sua narrativa. Na região Centro-Oeste, o foco está principalmente nas palavras de ordem e as manifestações foram pouco comentadas. Já na região Sudeste, há um misto de termos positivos, como "orgulho" e "lindo", termos relacionados à violência, como "bombas" "violência", além de palavras de ordem.

Características da Narrativa: além dos elementos-atores, reivindicações e contexto, observamos também a presença de conceitos que caracterizam o tipo de narrativa durante os protestos.

a) Localização w- abundam termos que permitem a localização da narrativa. Assim, em todas as regiões a frequência de termos indicando a localização (por exemplo, "paulista", em referência à Avenida Paulista em São Paulo ou "ipiranga", em referência à Avenida Ipiranga em Porto Alegre) é alta. Esses termos aparecem justamente nos conjuntos de dados de suas regiões, indicando que houve uma preocupação em localizar as narrativas 
dos protestos aos espaços onde estavam sendo produzidas. Esses dados se assemelham àqueles observados por Vallina-Rodriguez et al. (2011) na Espanha.

Observamos também que apesar de localizar a narrativa dentro de fronteiras geográficas, há referências entre regiões, principalmente à região Sudeste. Nos respectivos conjuntos de dados de todas as regiões, vemos a presença de referências a essa região tanto em hashtags quanto em conceitos. As cidades mais comentadas são, assim, São Paulo, Rio de Janeiro e Belo Horizonte (nos dados do Sudeste não foram encontradas menções a outras localidades). Vemos aqui que Rio de Janeiro, São Paulo e Belo Horizonte assumem, assim, o papel de protagonistas nos eventos de junho e que as demais regiões cumprem um papel de reverberação de seus protestos.

b) Hashtags panfletárias - um segundo elemento relevante, que pode ser observado nos termos mais frequentes do conjunto de dados, é o uso de hashtags como bandeiras, ou palavras de ordem. Algumas delas, nesse contexto, perdem seu sentido unicamente contextual e adquirem uma nova função: tornam-se em si mesmas manifestos. É o caso das hashtags mais comuns observadas, como \#vemprarua, \#changebrazil e \#ogiganteacordou. Seu uso é diferente das demais, uma vez que seu objetivo é propagar a ideia do protesto em si e das reivindicações, mais do que criar um contexto interpretativo para o tweet ou unificar a narrativa do que está acontecendo. Vemos, aqui, que o Twitter não funciona apenas como um espaço discursivo de relato, mas também de mobilização. Essa função é bastante semelhante à "panfletagem" observada por BASTOS, RAIMUNDO e TRAVITZKI (2012).

c) Valorização do "ao vivo" - uma das categorias que apareceu de forma sutil mas com bastante impacto nos dados foi aquela do "ao vivo". Tweets com marcadores temporais e locais direcionam bastante a narrativa para o aqui e o agora, indicando que o Twitter teve um papel fundamental nessa questão. Se observarmos isso em conjunto com o uso de hashtags localizadas, parece mais evidente esse papel. Esses dados reforçam o papel do Twitter como elemento narrativo do "ao vivo", também observado por Penney e Dadas (2013).

\section{Análise de rede das coocorrências}

Nesta última parte da análise, discutiremos as correlações e coocorrências dos conceitos encontrados nos dados. A Figura 2 mostra os termos que mais apareceram no conjunto de dados e as conexões mais fortes. Os termos mais centrais são aqueles que aparecem mais conectados à rede (maior centralidade). Os conceitos mais periféricos são aqueles que estão menos conectados aos demais (provavelmente mais localizados nos discursos, ou seja, com menor centralidade geral). O grafo está dividido por modularidade (vizinhança), onde os nós maiores são aqueles com mais conexões com os demais nós. 




Fig. 2. Grafo com a rede de coocorrências dos conceitos

A Figura 2 mostra quatro grandes grupos. O primeiro, em roxo, contém a maior parte das hashtags "de ordem". O segundo, em verde, está mais localizado nos termos que apareceram conjuntamente com "BH" (Belo Horizonte). O terceiro, em azul, está mais focado nos discursos de São Paulo (que, de longe, conforme vimos na Tabela 1, constitui-se no lugar mais citado e, por isso, contém também os atores e conceitos dos demais). O terceiro contém mais os discursos do grupo de tweets do Rio de Janeiro. É interessante notar como as hashtags \#protestosp e \#protestorj são extremamente centrais no grafo, indicando sua hiperconexão em todas as regiões. Pode-se observar a importância da função "ao vivo", da "localização" e do termo "tarifa", principal demanda do movimento que se encontra mais afastada do centro do grafo. Já palavras de ordem como "\#vemprarua" e "\#mudabrasil" são muito centrais.

É importante observar que os atores "polícia" e "protestos" estão quase juntos ao centro, mostrando seu protagonismo e associação nos discursos. Igualmente, a forte associação de "polícia" a "cuidado" e "violência" indica um discurso da ação entre esses atores. Do mesmo modo, "ao vivo" e "localização", características das narrativas, também estão conectados com "protestos", "polícia" e "violência". Isso evidencia o papel da narrativa ao vivo como uma maneira de reportar as ações da polícia e eventos violentos. Essa "violência" que parece marcadamente associada à "polícia" também está associada 
a "bombas" e "gás" (como a conexão entre ambos é muito forte, observamos que os termos aparecem quase sempre juntos), sobretudo nos protestos de Belo Horizonte.

Vemos também que as hashtags com sentido "panfletário" (BASTOS, RAIMUNDO e TRAVITZKI, 2012) tendem a apresentar maior articulação (vide o módulo) e aparecem desconectadas dos demais conceitos. Isso também evidencia sua diferente função discursiva e as contrapõe às hashtags mais localizadas, como \#protestosp e \#protestorj, que pertencem a grupos diferentes. Estas últimas parecem ter como função a unificação das narrativas, conforme proposto por Cancian, Moura e Malini (2013), devido à sua maior proximidade para com os atores e demandas da rede e sua não clusterização em torno de um módulo, conforme as hashtags mais panfletárias.

As coocorrências por região demonstram pequenas diferenças da figura geral. Na Figura 3, temos a rede de coocorrências mais fortes localizadas na região sudeste. Vemos que algumas associações são bastante fortes, como "tarifa" e "ônibus", que demarcam a principal reivindicação presente no corpus, assim como "violência" e "momento". É interessante notar a localização dos termos por hashtag: há um cluster em torno de \#protestorj, outro em torno de \#protestosp e um terceiro em torno de \#protestobh. A presença de hashtags panfletárias em um cluster também mostra sua importância e sua tendência em aparecer conjuntamente.



Fig. 3. Coocorrências da região Sudeste 


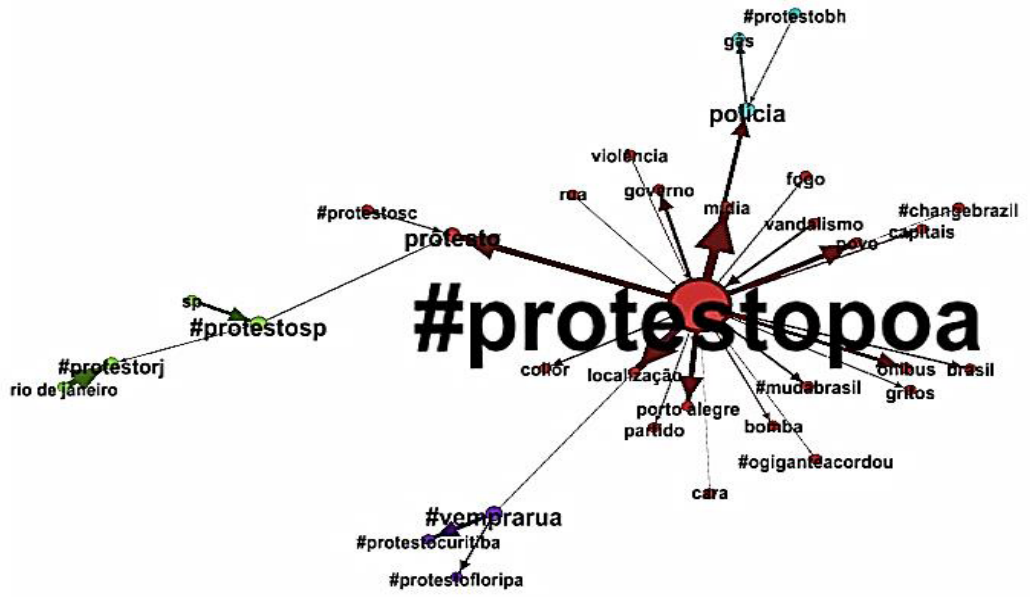

Fig. 4. Coocorrências região Sul

Na Figura 4, temos as coocorrências mais fortes na região Sul. Enquanto que ao centro do grafo aparece a hashtag \#protestopoa (localização) conectada aos atores e demandas, vemos em um cluster verde referências a São Paulo e Rio de Janeiro através de suas hashtags respectivas. Novamente, observamos uma localização. Também é interessante notar as palavras associadas aos protestos em Porto Alegre como "vandalismo", "gritos" e "fogo", conforme já vimos anteriormente.

Na Figura 5, vemos a imagem das coocorrências dos protestos na região Centro-Oeste. Vemos, de novo, coocorrências bastante específicas e localizadas, centralizadas em torno de dois clusters, um focado no \#protestodf e o outro, no \#protestosp. Interessante notar que em torno deste último estão também outras hashtags localizadoras. Vemos também algumas particularidades como a presença do cluster conectando os protestos às redes sociais (em azul), bem como as referências à "direita" e à "esquerda". 

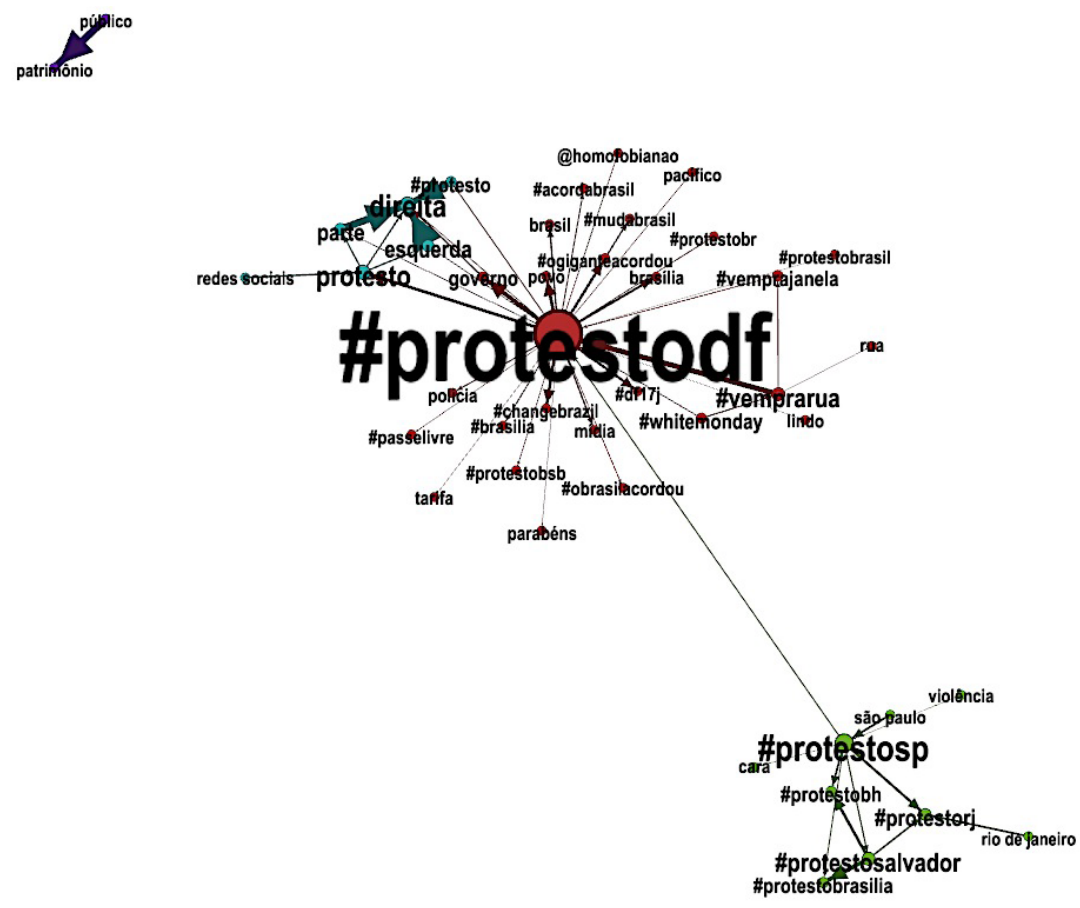

Fig. 5. Co-ocorrências da região Centro-Oeste

Na Figura 6 aparece a região Nordeste. Vemos um primeiro cluster central em torno da hashtag \#protestoce e, a seguir, um segundo cluster em azul, conectando "protesto" e "\#protestosp". Observamos que neste segundo cluster, conectado a "\#protestosp" está o "\#passelivre" e o "tarifa", que representam as demandas. Vemos também a ocorrência dos adjetivos "lindo" e "orgulho" no primeiro cluster.

Finalmente, no último grafo temos a região Norte (Figura 8). Esta é a única região onde a centralização em torno de uma única hashtag é menor. O conceito mais central, ao contrário das demais, é "protesto". Também neste grafo, vemos a profusão de conceitos positivos e adjetivos relacionados ao evento, como "orgulho", "boa", "lindo" e etc. O conceito "pacífico", por exemplo, aparece apenas aqui. Ao contrário da região Sul, a narrativa aqui é a que contém menor volume de termos relacionados com a violência entre todas as regiões.

Vemos assim que, embora a maior parte dos grafos das regiões tenha um padrão semelhante (centralização em torno de hashtags locais narrativas e clusters com hashtags de outras regiões; mesmos atores, demandas e conceitos), há algumas diferenças. O discurso na região Sul é mais violento, enquanto o da região Centro-Oeste foca o governo com mais intensidade, e as regiões Norte e Nordeste parecem amenizar a questão negativa e falar mais de conceitos positivos, como "orgulho", "lindo" e "pacífico" aos protestos. 


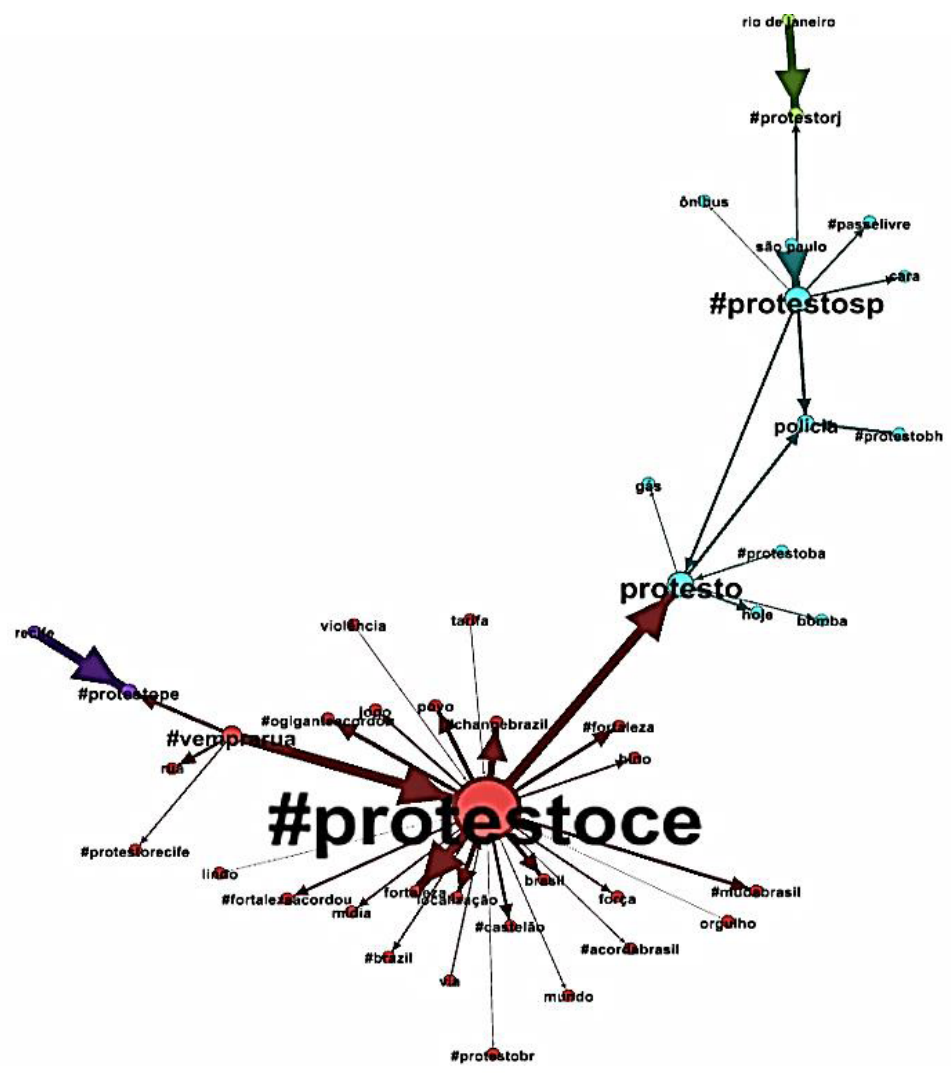

Fig. 6. Coocorrências da região Nordeste

Essas associações demarcam os campos linguísticos estabelecidos por Bourdieu (1977), e sinalizam os discursos mais presentes nos dados analisados. Há um discurso panfletário e um narrativo dos protestos que coexistem conjuntamente. Enquanto o primeiro reflete a necessidade de mobilizar as pessoas, o segundo reflete a própria narrativa dos eventos (CANCIAN; MOURA; MALINI, 2013), "ao vivo", além de localizá-la, e traduzi-la como violenta, especialmente entre os atores principais ("polícia" e "protestos"), principalmente na região Sul. Ao mesmo tempo, vemos também o uso de hashtags que demarcam o contexto dessas narrativas e que têm uma posição mais central nos grafos, enquanto hashtags que demarcam ação mais panfletária (BASTOS, RAIMUNDO e TRAVITZKI, 2012) ficam mais conectadas entre si e menos conectadas ao contexto dos protestos, ressaltando as funções do Twitter, proposta por Gleason (2013). 

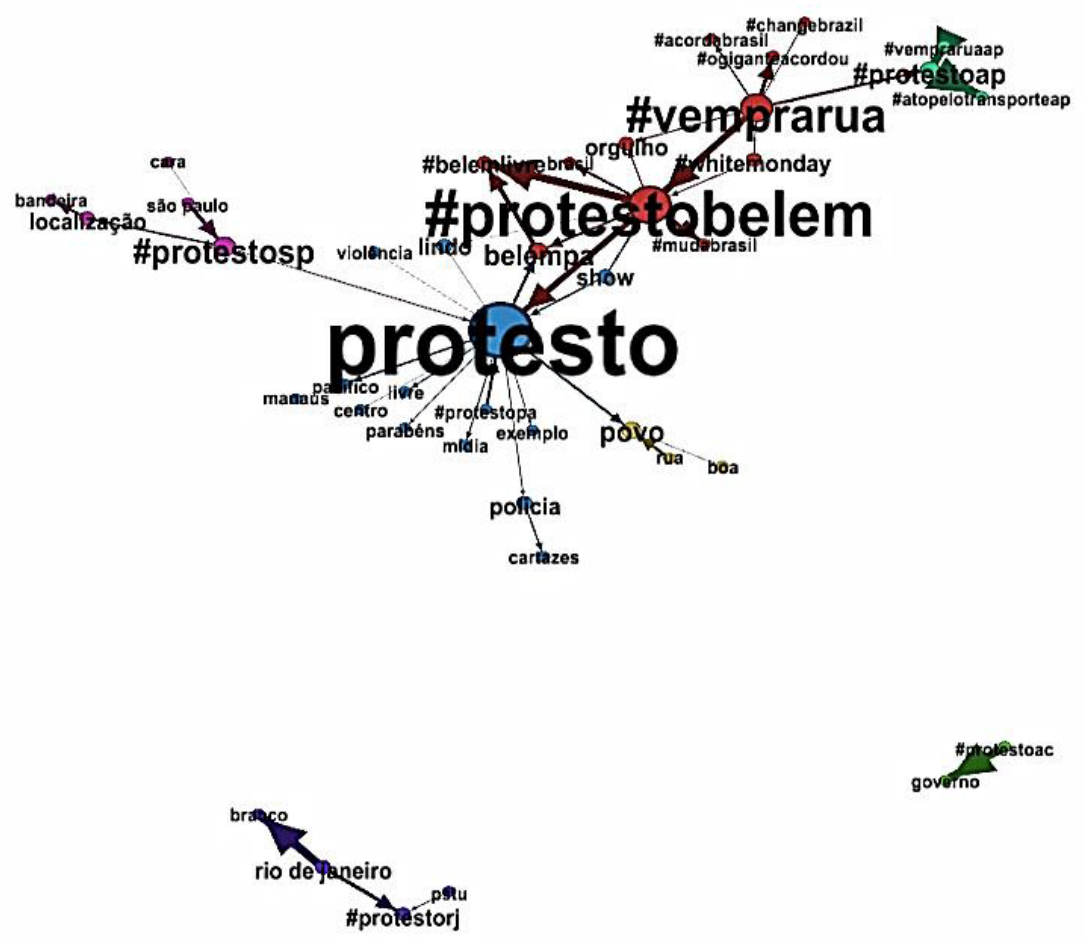

Fig. 7. Co-ocorrências região Norte

\section{Conclusões}

Nosso objetivo neste trabalho foi discutir o discurso dos protestos de junho de 2013 no Brasil a partir de um recorte específico de tweets. Nossas questões focaram a identificação e discussão das características dos discursos sobre esses protestos, notadamente a questão da localização e do "ao vivo", bem como a presença comum de determinados atores e demandas. A respeito dessa questão, pudemos observar a presença de atores relativamente comuns na maior parte das regiões (como "manifestantes" e "polícia", por exemplo), indicando a pluralidade de participação no movimento.

No segundo ponto, que objetivava verificar as diferenças de discurso nas regiões, observamos pequenas diferenças sutis e uma estrutura relativamente homogênea que fala de um protesto cujos atores - protesto, polícia, governo e mídia - aparecem interligados com os protestos associados a conceitos mais positivos (notamos a presença do adjetivo "lindo" em todas as redes). A violência aparece pouco, com exceção do grafo da região Sul. 
A rede de coocorrências reforça essas análises, mostrando narrativas com um fio condutor bastante parecido, como a narrativa do "ao vivo" e a presença de determinados atores. Entretanto, observamos algumas diferenças importantes entre as regiões, tais como a ausência de termos relacionados ao governo, por exemplo.

Essas observações indicam que, apesar de um fio condutor principal, que permeou as narrativas de todas as regiões, não houve uma percepção única em todos os discursos. Observamos esses dois fios como sendo o "narrativo" e o "panfletário", ou discurso mobilizador. Embora o discurso "panfletário" tenha mais unicidade em torno das hashtags utilizadas, a narrativa dos eventos apresentou variações nas diferentes regiões, conforme discutimos.

Outros elementos observados trazem a questão do foco narrativo dos protestos, principalmente através da associação dos atores principais a hashtags mais contextuais, enquanto as mais focadas em ações panfletárias associavam-se entre si. Chama ainda a atenção a ausência de centralização do discurso em torno de demandas, mesmo quando o discurso é patentemente panfletário. Por outro lado, o discurso narrativo, focado na localização dos eventos e no "ao vivo", é particularmente presente no Twitter e bastante esperado.

A ausência de demandas e a homogeneização dessas características também parece reduzir a função democrática do Twitter enquanto espaço de organização e demanda, dando-lhe uma função imediatista nessas narrativas. Essas características delimitam o "campo linguístico" dos protestos no Twitter e as possibilidades discursivas da ferramenta. Notadamente, a homogeneização da estrutura das coocorrências parece sugerir o Twitter não como um espaço de debate e organização, mas de narrativa e mobilização.

Raquel Recuero é professora e pesquisadora do Programa de Pós-Graduação em Letras e dos cursos de Jornalismo e Publicidade e Propaganda da Universidade Católica de Pelotas raquelrecuero@gmail.com

Gabriela Zago é doutoranda em Comunicação e Informação pela Universidade Federal do Rio Grande do Sul e professora dos cursos de Design da Universidade Federal de Pelotas.

gabrielaz@gmail.com

Marco Toledo Bastos é pós-doutorando no centro HASTAC da Duke University. É pós-doutor e doutor em Ciências da Comunicação pela Universidade de São Paulo.

mtabastos@gmail.com 


\section{Referências}

BARDIN, L. Análise de Conteúdo. Lisboa: Edições 70, 2004.

BASTOS, M. T.; RAIMUNDO, R. e TRAVITZKI, R. Gatekeeping Twitter: message diffusion in political hashtags. Media, Culture \& Society, March 2012, v.35: 260-270, doi:10.1177/0163443712467594.

BOURDIEU, P. A economia das trocas simbólicas. São Paulo: Perspectiva, 1977.

Language and Symbolic Power. Massachusetts: Harvard University Press, 1991.

BOYD, D.; GOLDER, S.; LOTAN, G. Tweet, Tweet, Retweet: Conversational Aspects of Retweeting on Twitter. In: HICSS-43. IEEE: Kauai, HI, 2010.

BURNS, A.; ELTHAM, B. Twitter Free Iran: an Evaluation of Twitter's Role in Public Diplomacy and Information Operations in Iran's 2009 Election Crisis. In: Communications Policy \& Research Forum, Sydney, 2009.

CANCIAN, A; MOURA, G; MALINI, F. A tecnopolítica das multidões inteligentes: uma análise do \#25S no Twitter. In: INTERCOM SUDESTE, 2013, Manaus. Anais... Intercom, 2013.

CASTELLS, M. Networks of Outrage and Hope. New York: Polity Press, 2012.

FOUCAULT, M. A Ordem do Discurso. São Paulo: Edições Loyola, 1999.

GLEASON, B. \#Occupy Wall Street: Exploring informal learning about a social movement on Twitter. American Behavioral Scientist v. 57, n. 7, p. 966-982, 2013.

GUTIERREZ, B. As revoltas em rede como uma nova arquitetura do protesto. Revista Alegrar, n. 12, 2013. HOWARD, P.; HUSSAIN, M. The Role of Digital Media. Journal of Democracy, v. 22, n. 3, 2011, p. 35-48.

KRIPPENDORF, K. Content Analysis, An Introduction to Its Methodology. 3.ed. Thousand Oaks: Sage, 2012.

LINDGREN, S.; LUNDSTRÖM, R. Pirate Culture and Hacktivist Mobilization: The cultural and social protocols of \#WikiLeaks on Twitter. New Media and Society, v. 13, n. 6, p. 999-1018.

MALINI, F.; ANTOUN. H. A Internet e a rua. Porto Alegre: Sulina, 2013.

OSGOOD, C. The representational model and relevant research methods. In: POOL, I. de S. Trends in Content Analysis, Urban. Illinois: Univ. of Illinois Press, 1959.

PENNEY, J; DADAS, C. (Re)Tweeting in the service of protest: digital composition and circulation in the Occupy Wall Street movement. New Media \& Society, OnlineFirst, p. 1-17, 2013.

TORET, J. Una mirada tecnopolítica sobre los primeros días del \#15M. In: ALCAZAN, ARNAUMONTY, AXEBRA, QUODLIBETAT, SIMONA LEVI, SUNOTISSIMA, TAKETHESQUARE y TORET, Tecnopolitica, Internet y R-evoluciones sobre la Centralidad de Redes Digitalez en \#15M. Barcelona: Icaria Editorial, 2012.

VALLINA-RODRIGUEZ, N.; SCELLATO, S.; HADDADI, H.; FORSELL, C; CROWCROFT, J.; MASCOLO, C. Los Twindignados: The Rise of the Indignados Movement on Twitter. In: SocialCom'12. Amsterdam, 2012.

WASSERMAN, S.; FAUST, K. Social Network Analysis. Methods and Applications. Cambridge, Cambridge University Press: 1994. 